\title{
Evaluation of Soil Foundation by Integration of Geophysical and Geotechnical Methods at West Kom Umbo Area, Aswan, Egypt
}

\author{
Hafeez THA ${ }^{1 *}$, Bekhet $M^{1}$, Bakr MA ${ }^{1}$ and Hamdy \\ $\mathbf{A}^{2}$ \\ ${ }^{1}$ Department of Geology, Faculty of Science, Al-Azhar \\ University, Cairo, Egypt \\ ${ }^{2}$ Senior Engineering Geophysicist, Misr Consult Groub, \\ Cairo, Egypt \\ *Corresponding author: Tharwat H Abdel Hafeez, \\ Department of Geology, Faculty of Science, Al-Azhar \\ University, Cairo, Egypt
}

Received: April 15, 2021; Accepted: May 11, 2021; Published: May 18, 2021

\begin{abstract}
This research includes combining a geophysical study with a geotechnical study to explore different soil types in the western Kom Umbo area. First: The geophysical study, which includes Electrical Resistivity and Ground Penetrating Radar were conducted to determine the subsurface layers, and to identify "gaps and soil heterogeneity, if any."
\end{abstract}

Fifty Vertical Electrical Soundings (VESs) were made to determine the layers and the electrical resistivity of the layers. Twelve Ground Penetrating Radar profiles (GPR) have also been created to identify soil homogeneity, gaps, geotechnical properties and to identify "existing cracks or faults. Second: the geotechnical study, which includes the study of a different boreholes in all areas of the study to determine the different layers and geotechnical properties.

And field tests (standard penetration test) were done and laboratory tests (such as sieves analysis). And how to determine the degree of soil quality and the ability to build on it. From the above, we can combine the results of geophysics with the results of the geotechnical study to evaluate of soil foundation and to obtain confirmed and accurate information about the nature of the soil in the study area and its homogeneity and determine the possibility of exploiting and benefiting from it in industrial facilities, large, small, residential buildings, green spaces.

According to this research the study area is generally divided into two layers, the first layer consists of gravel sand which has a resistivity range from 4189 to 38033 and the second layer is sand which has a resistivity value ranging from 1224 to $9682 \mathrm{ohm} / \mathrm{m}$. and in the present study we have achieved the next procedure on the processed GPR data, displaying 2D profiles that contain the expected anomalies. Because the study area is saturated with silty sand and gravel, part of radar waves is attenuated and the reflections from the subsurface materials are weak. Results with the $100 \mathrm{MHz}$ antennae are the resistive sand, gravel is a very good GPR target, and horizontal layering and stratification are evident throughout the deposit. Engineering studies on samples which collected from different sites in the study area reveal that, the results of uniformity coefficient $(\mathrm{Cu}$ ) ranging between 3.15 (Very uniform) to 35.56 (Non-uniform). The results of coefficient of gradation range between 0.61 (poorly graded) to 2.41 (Well graded).

Keywords: Kom umbo; Electrical resistivity; Ground penetrating radar; Soil foundation

\section{Introduction}

Recently, the Egyptian Government pays special attention to develop the West Kom Umbo area, which called El-Gallaba Plain. Such development planning has already started with establishing PV power plants in the Benban project. Furthermore, it is expected to continue and include agriculture, industrial and urban development projects. However, these development plans should be based on appropriate land use planning, which must consider the geological and geotechnical soil properties, as well as the impact of natural geological hazards. The proposed study will tackle this issue using the integration of geophysical and engineering geology.
The study area is located northwest of Aswan city, in the Western Desert between latitude $24^{\circ}$ to $25^{\circ} \mathrm{N}$ and longitude $31^{\circ} 30^{\circ}$ to $33^{\circ}$ E, and comprises the El-Gallaba Plain, the western part of the Kom Umbo basin, and Wadi El-Kubanyia (Figure 1). It is characterized by an arid climate with desert-like conditions. Although rainfall is not significant throughout the year, some rare and irregular storms take place over. (Area $5336 \mathrm{~km}^{2}$ ).

\section{Scope of the Present Study}

The main objective of the present work is subdivided into two main parts. The first part dealt with geophysical investigations and the second part with the geotechnical properties of the foundation 


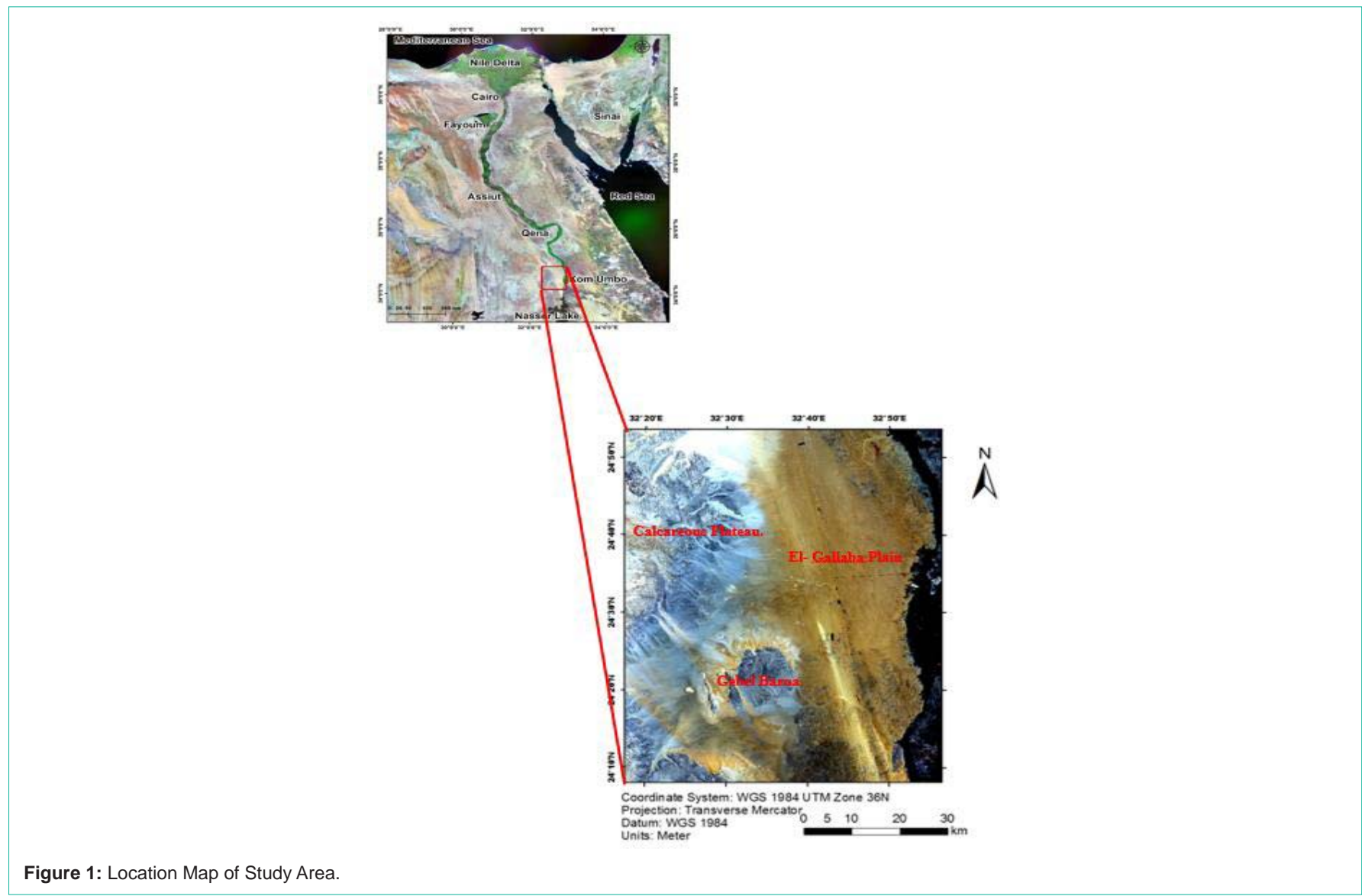

bed.

To attain the first part the geophysical investigations dealt with Electrical Resistivity and Ground Penetrating Radar to evaluate the foundation Soil properties as well as, their interpretation in terms of subsurface sedimentary structures, the evaluation of the quality and geotechnical parameters and consequently the material competence.

The second part includes the geotechnical properties which including 40 stratigraphic sections were studied and distributed in the study area and Also, how to derive the most important geotechnical parameters and apply them with depth to determine the degree of soil quality and the ability to build on it.

\section{Geology and Tectonics}

The investigated site lies in the western extension of the Kom Umbo Basin and has most probably been affected by the geo-structure setting that shaped the basin [1].

This basin received a significant amount of surface runoff during the rainy season (in past) from the eastern Red Sea Mountains range and western calcareous plateau as well. Topographically, El-Gallaba Plain is relatively flat (Figure 1), and covered by fluvial deposits (sand and gravel) brought by an old E-W striking river course (wadi), which is older in age than the present Nile River [1]. These sediments are known as Protonile Deposits (Qn1) on the geological map of the study area (Figure 2). Wadi El-Kubanyia is the western remnants of this ancient wadi system.
The connection between the present-day Wadi El-Kubanyia and its delta (El-Gallaba Plain) is not known yet, because it is completely covered by an active longitudinal sand dune.

Geologically the area under investigation is an important role in the evaluation of soil quality. Moreover, the identification of the Lithological characteristics and structural impacts on the building will give a good evaluation of the foundations.

The geology of the Aswan area is reviewed from the previous publication [2-5].

These studies assess that the investigated region belongs to the Kom Umbo sub-basin of southern Egypt that comprises a different lithostratigraphic succession of the late Paleozoic, Mesozoic-Tertiary. Along the surface, several lithological units are ranging in age from Cretaceous to Quaternary. This succession includes the following rock units (from base to top) as following.

The top sediments in El-Gallaba Plain as described in the official geological map of Aswan, Egypt (sheet NG-36 B with scale 1:250 000) are typically characterized as sand, the mix of gravel/sand and gravel sediments of fluvial and aeolian deposits (Figure 2) [6]. These surficial sediments originated from different sources and different directions.

The tectonic framework of the El-Gallaba Plain is related to the Last African Orogenic belt [2,7]. The entire Nile Valley in Egypt is controlled by wrench faults that are generally parallel either to the Gulf of Suez or to the Gulf of Aqaba directions [8]. The stratigraphic 


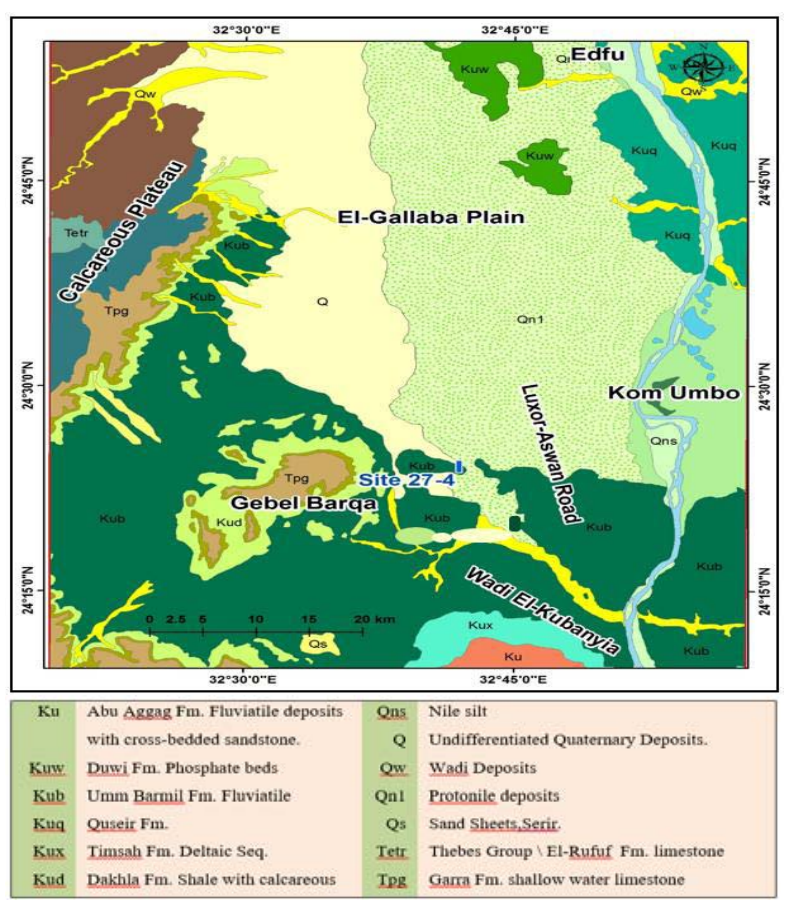

Figure 2: Geological map of the study area after geological survey of Egypt et al. [6].

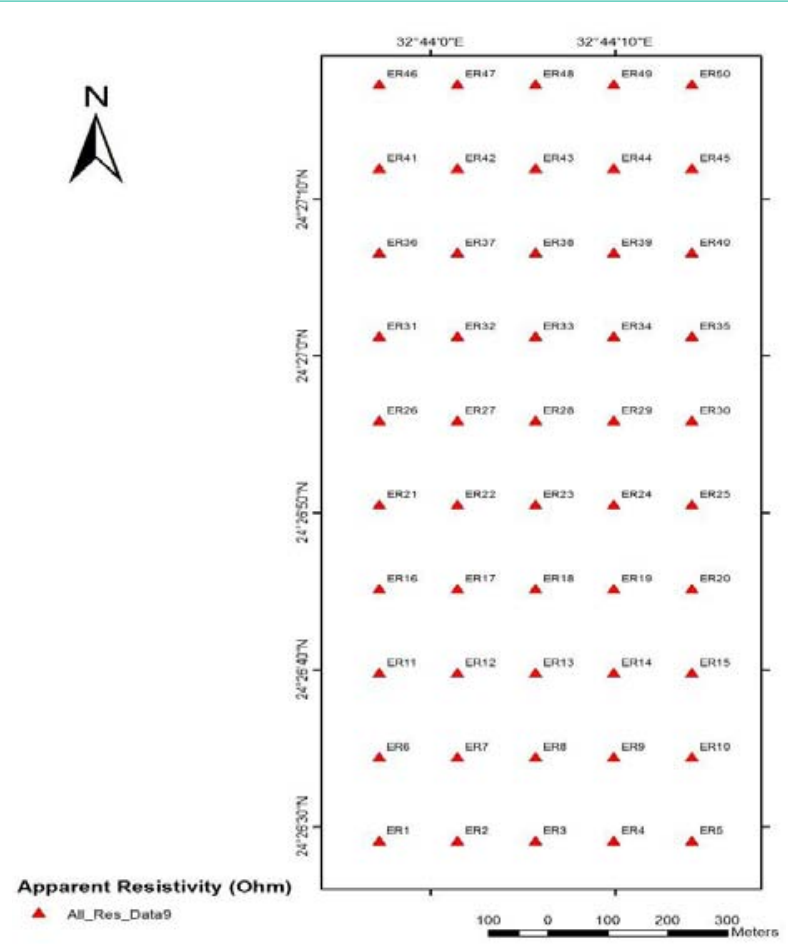

Figure 3: Location of Vertical Electrical Soundings in Study Area.

sequence of the study area ranges in age from Pre- Cambrian to Quaternary. The Pre-Cambrian rocks consist mainly of igneous and metamorphic rocks. The sedimentary section overlying the basement complex ranges in age from Paleozoic to Recent. Thus, the study area has been affected by the same structural deformation processes that formed the Nile Valley and shaped the Kom Umbo basin.
Groundwater levels were measured around the area of the study area based on field information collected from drilled wells. The depth to water ranges from 35 to $70 \mathrm{~m}$ and sometimes 0 as in Kurkur Oasis, south of the investigated site. The total depth of the wells ranges from 100 to $150 \mathrm{~m}$, and a few of them even reach the basement rocks which means the sedimentary cover in the study area is relatively 
Table 1: Resistivities, Thicknesses of each layer.

\begin{tabular}{|c|c|c|c|c|c|c|c|c|c|}
\hline & \multicolumn{2}{|c|}{ Layer 1} & \multicolumn{2}{|c|}{ Layer 2} & & \multicolumn{2}{|c|}{ Layer 1} & \multicolumn{2}{|c|}{ Layer 2} \\
\hline & p1 & h1 & p2 & h2 & & م1 & h1 & p2 & h2 \\
\hline VES 1 & 11663 & & 1224 & & VES 26 & 8470 & 1.47 & 4574 & .. \\
\hline VES 2 & 13144 & 1.84 & 3550 & ... & & 15171 & 1.7 & 3444 & \\
\hline VES 3 & 15628 & 1 & 3926 & 12.6 & VES 28 & 20200 & 1.85 & 2772 & $\cdots$ \\
\hline VES 4 & 11629 & 2.33 & 4170 & $\ldots$ & VES 29 & 21324 & 1.93 & 3209 & ... \\
\hline VES 5 & 11233 & 1.71 & 6663 & & VES 30 & 21294 & 2 & 5501 & \\
\hline VES 6 & 14929 & 1 & 5039 & 12.6 & ES 31 & 11191 & 1.54 & 4170 & \\
\hline VES 7 & 11183 & 2 & 5799 & $\ldots$ & & 16674 & 1.51 & 4095 & . \\
\hline VES 8 & 15248 & 1.79 & 7770 & ... & VES 33 & 23004 & 1.34 & 4057 & $\ldots$ \\
\hline VES 9 & 30670 & 1.13 & 5803 & ... & VES 34 & 19162 & 1.24 & 5246 & $\ldots$ \\
\hline VES 10 & 15284 & 1 & 6472 & $\ldots$ & VES 35 & 23662 & 1.5 & 5008 & .. \\
\hline VES 11 & 4189 & 8.69 & 5750 & & VES 36 & 7812 & 1.68 & 2773 & \\
\hline VES 12 & 20497 & 1 & 6822 & & VES 37 & 8145 & 1.59 & 2970 & \\
\hline VES 13 & 20903 & 1 & 9682 & ... & VES 38 & 17550 & 1.32 & 4080 & $\ldots$ \\
\hline VES 14 & 20497 & 0.99 & 6822 & ... & VES 39 & 33044 & 1.32 & 4377 & .. \\
\hline VES 15 & 11820 & 1 & 2370 & ... & VES 40 & 38033 & 1.32 & 4377 & $\cdots$ \\
\hline VES 16 & 17229 & 1 & 5735 & ... & VES 41 & 10997 & 1.34 & 3167 & $\ldots$ \\
\hline VES 17 & 18240 & 1.1 & 5650 & $\ldots$ & VES 42 & 9839 & 1.68 & 3305 & \\
\hline VES 18 & 20561 & 1 & 5889 & ... & VES 43 & 18251 & 1.66 & 3398 & 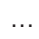 \\
\hline VES 19 & 13215 & 1.54 & 5507 & $\ldots$ & VES 44 & 25536 & 1.66 & 3332 & $\cdots$ \\
\hline VES 20 & 26531 & 1.03 & 7077 & $\ldots$ & VES 45 & 22870 & 1.8 & 3708 &. \\
\hline VES 21 & 10088 & 1.85 & 4377 & ... & VES 46 & 18310 & 1.57 & 1297 & .. \\
\hline VES 22 & 25023 & 1.55 & 6066 & ... & VES 47 & 25933 & 1.25 & 1940 & $\cdots$ \\
\hline VES 23 & 25516 & 1.57 & 3152 & $\ldots$ & VES 48 & 14653 & 1.79 & 2606 & $\cdots$ \\
\hline VES 24 & 27698 & 1.22 & 5461 & $\ldots$ & VES 49 & 14139 & 1.73 & 2287 & $\cdots$ \\
\hline VES 25 & 35509 & 1.24 & 7653 & $\ldots$ & VES 50 & 17121 & 1.38 & 2041 & $\cdots$ \\
\hline
\end{tabular}

small. This observation is supported by the geology found in Aswan city, where the granite rocks and Nubian Sandstone crop out. On the other hand, the plain area west of Aswan sector has a somewhat fixed lithology as listed here from top to bottom: Sandstone (range from 20 to $30 \mathrm{~m}$ thickness), Mudstone (range from 30 to $40 \mathrm{~m}$ thickness), sandstone (range from 20 to $30 \mathrm{~m}$ thickness), which represents the main aquifer and finally mudstone around $20 \mathrm{~m}$ thickness, followed by the basement rocks. The water analysis results conducted by Gaber et al., [9] revealed that the groundwater is of very good quality for human consumption and similar in its physical-chemical parameters to the river Nile water.

\section{Geophysical Studies}

This paper aims to introduce and describe the geophysical investigations in the study area, which included geoelectrical measurements, and Ground Penetrating Radar surveys. It will also elucidate the fieldwork and acquisition of the geophysical data as well as the processing of the acquired data using computer software and eventually the data interpretation, in addition to the consistency between the geophysical and geotechnical results.

\section{Geoelectric measurements}

Instruments and field operations: We adopted Vertical Electrical
Sounding (VES) technique using Wenner array distribution. In this method, the measuring point is constant, while the spacing between the electrodes (a) is increased gradually in form of $2,4,6,8,10,20 \mathrm{~m}$, respectively. This means that in each measuring point (ER) 6 readings were obtained. These readings showing the vertical variation in soil resistivity up to $10 \mathrm{~m}$ depth, which normally increases the depth of the current potential with increasing spacing between electrodes (a).

In this study 50 points of VES (from ER1 to ER50, Figure 3) using the aforementioned technique. It was obvious that the surface layer composed of gravel with friable sands, which has very high resistivity to the limit to prevent the flow of the electric current. To overcome this problematic situation, we applied the following steps, respectively:

- Utilizing iron spikes with $90 \mathrm{~cm}$ in length.

- Increasing the penetration of the electrodes into the ground up to $80 \mathrm{~cm}$.

- Pour saline water around the electrode to facilitate the electric conductivity and reducing the surface resistance.

- Adding multi spikes at the same electrode point to increase the contact between the surface soil and the electrode.

\section{Analysis of geoelectric data}

Interpretation of the geoelectrical data is carried out for the resistivity sounding to recognize the subsurface rock sequence in the form of successive geoelectrical layers having definite resistivities, depths, and thicknesses. The shallow subsurface structures such as faults and fractures can also be detected by such interpretation.

Interpretation of resistivity soundings: The measured vertical electrical soundings are illustrated in (Figure 3 ) and the interpretation of the acquired resistivity sounding data is carried out in two simultaneous phases (qualitative and quantitative).

The integration between both procedures enhances the results and emphasizes the final conclusions. The steps followed in the interpretation of the acquired data qualitatively and quantitatively are:

\section{Qualitative Interpretation}

Examining the types of the collected apparent resistivity curves, a number of resistivity pseudo-sections and apparent resistivity maps at $A B / 3$ separations constitute the main items to qualitatively interpret the resistivity data in the present study.

\section{ISO-apparent resistivity contour maps}

The apparent resistivity values vary from about $4277 \Omega . m$ at the West part (VES No. 11) to about $42271 \Omega . m$ at the East part (VES No. 40). The study of this map indicates a relatively general decrease in the electrical resistivity towards the North West and western parts of the area, while it increases towards Eastern and North East parts (Figure 4).

\section{Quantitative Interpretation}

The distribution of the vertical electrical Sounding curves in the study area is consistent and reflects the subsurface geologic conditions. The interpretation of these resistivity curves shows a 

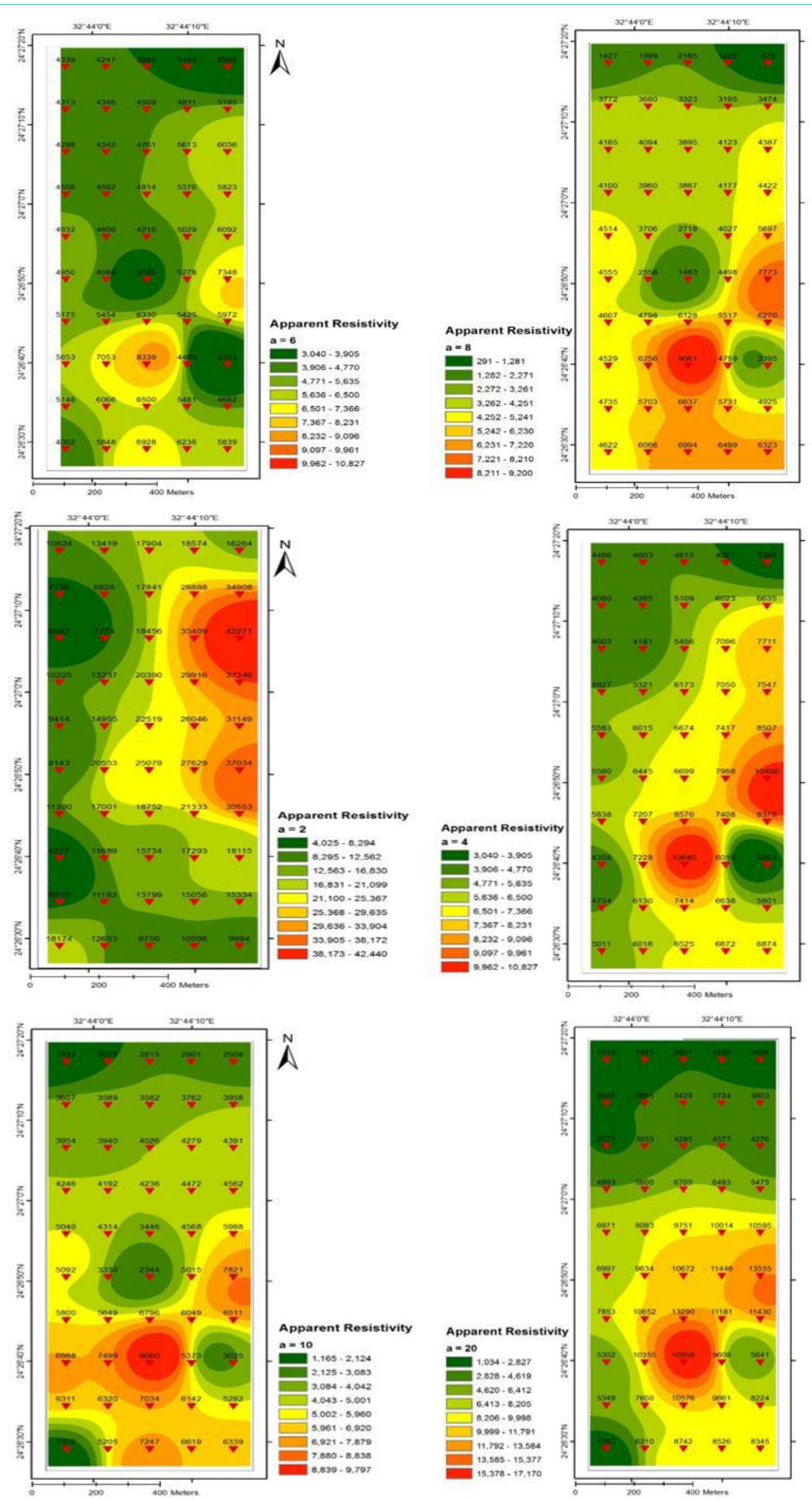

Figure 4: Apparent resistivity contour map with Wenner electrode spacing (a) $2 m, 4 m, 6 m, 8 m, 10 m, 20 m$ respectively. 


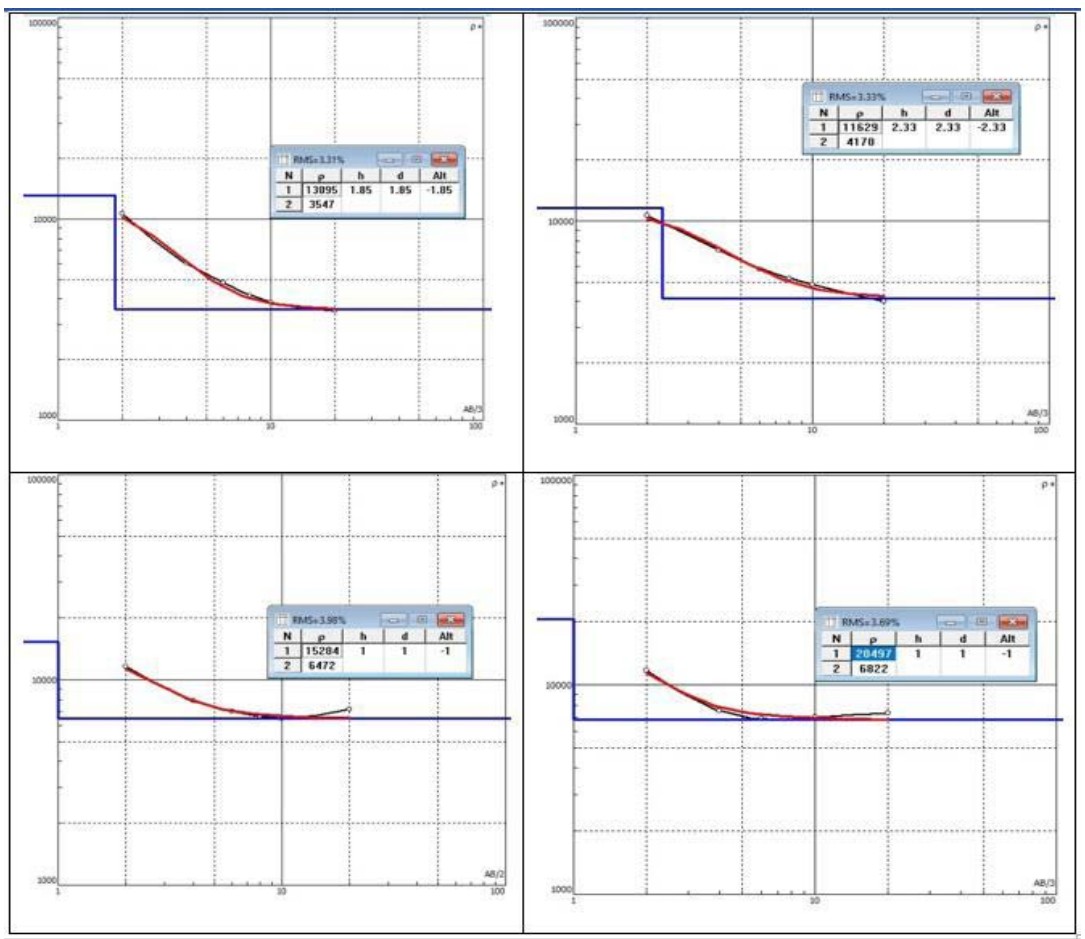

Figure 5: The interpretations of the vertical electrical sounding curves (IPI-2).

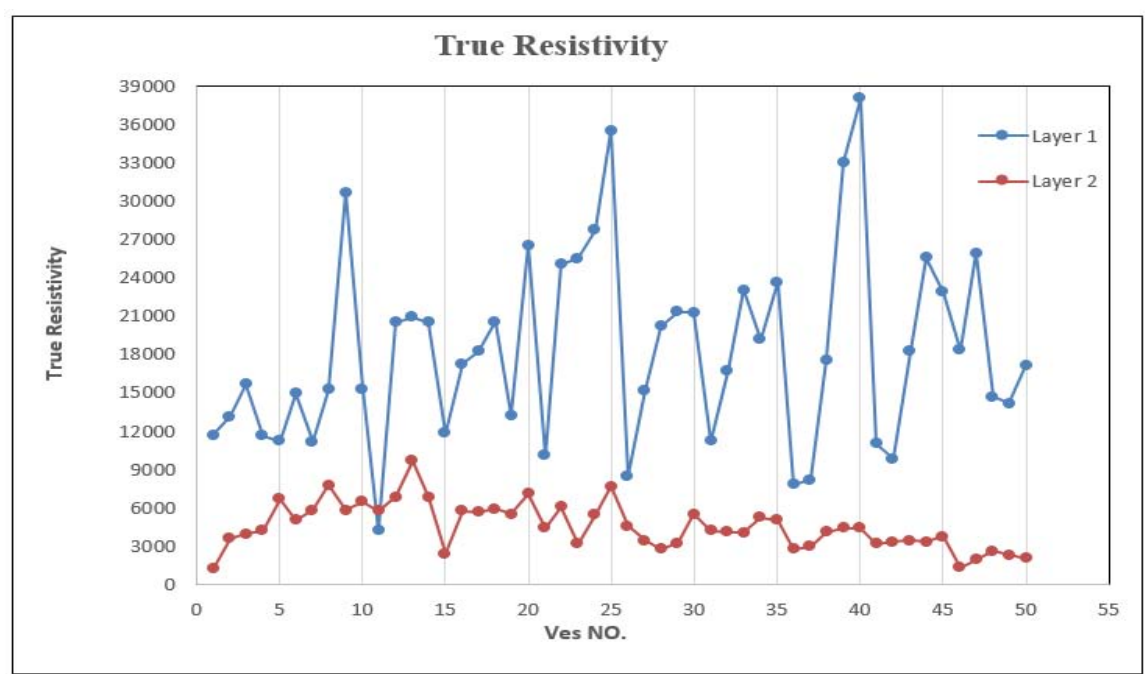

Figure 6: True resistivities of first layer and second layer of the study area.

relative wide range of values in their resistivities.

Also, the interpretation of the vertical electrical sounding curves exhibits that, the number of interpreted units is two and the true resistivities of these layers range between less than $1224 \Omega$.m to more than $38033 \Omega$.m. Also, the thicknesses of these layers vary from a sounding station to the other (Table 1). The interpretations of the vertical electrical sounding curves are shown in (Figure 5).

These true resistivities of first layer and second layer of the study area are shown in chart (Figure 6).

\section{Ground Penetrating Radar (GPR)}

GPR uses pulses of electromagnetic energy (radio waves). Their frequencies are usually between 10 and $2000 \mathrm{MHz}$ that are propagated into the ground by a transmitting antenna. At the same time, a receiving antenna detects the waves that are reflected up to the ground surface when the transmitted pulse encounters a subsurface interface across which exists an electromagnetic impedance contrast. GPR systems are classified as air-coupled or ground-coupled systems. In air-coupled systems, the antennas are typically 150 to $500 \mathrm{~mm}$ above the surface. In ground-coupled systems, the antennas are in 
full contact with the ground.

\section{Acquisition of GPR Data}

In the present study, the GPR survey was carried out using the RAMAC/GPR system (MALA-Geosciences, Sweden). This is a portable, digital subsurface radar system designed for a broad range of geological and engineering applications. The system is consisting of a control unit transmitter and receiver antennae, electronics, optical fibers with SM-connectors, power source, encoder for distance measurement, and Data Collection Computer. The system components after installation together with for $100 \mathrm{MHz}$ antennae, respectively, this system works using low-frequency antennae, using the low-frequency antennae, reflection profiling can be carried out. The reflection profiling technique achieves continuous subsurface coverage to probing depth along the survey line. This technique is the most common type of operation in which the transmitting and receiving antennae are mounted at a fixed separation and the survey is performed by moving the antenna array along with the measurement profile. In the present study, the $100 \mathrm{MHZ}$ antennae were simultaneously used in a grid pattern covering the area under investigation for a total of 12 GPR lines.

\section{Processing of GPR Data}

The ground-penetrating radar files were processed using REFLEX-W [10] software version 7.2, the row data are corrected and processed using a number of processing steps have been applied including time zero correction to ensure that all traces contained the same zero nanoseconds start time, Dewow filter to remove lowfrequency bias in the GPR traces, Gain correction to enhance the appearance of later arrivals due to the effect of signal attenuation and geometrical spreading losses [11], Background removal lines resulting from surface reflections, Bandpass filter in order to eliminate highfrequency components, and finally Running Average to smooth the GPR image.

\section{Interpretation of GPR Data}

GPR data interpretation is an essential step to determine the location of the anomalies that appear on the processed sections and discriminate them from the other undesired reflections. The results are displayed in three categories: one-dimension trace (1D), twodimension cross-section (2D), and three-dimension block view (3D). In the present study, we have achieved the next procedure on the processed GPR data, displaying 2D profiles that contain the expected anomalies. Because the study area is saturated with silty sand and gravely sand, part of radar waves is attenuated and the reflections from the subsurface materials are weak. Results with the $100 \mathrm{MHz}$ antennae are shown in Figure 7. The resistive sand and gravel are very good GPR target and horizontal layering and stratification are evident throughout the deposit $[12,13]$.

\section{Geotechnical Study}

This study is concerned with the study of the physical and engineering properties of the soils encountered in the West Kom Umbo, as well as their effects on the construction stability. It aims also at providing alternative solutions for the excepted concerned problems of these rocks and soils. This target will be companies with the previously obtained geologic information.

By using the different methods of geology (sample collection and Geophysics technique). The result was the foundation bedrock at West Kom Umbo composed of two layers besides.

The surface layer is the layer consists of that covers the area with a mixture of graded sand and gravel some site.

The second layer compacted of graded sand some silt and gravel (Figure 8) shows a geotechnical section.

\section{Physical and Engineering Properties of the Rocks}

The type of foundation bed at the west Kom Umbo area is soils. Soils are very complex materials and widely varied soils consist of particles that stick together in either dry or wet state display cohesion. Cohesion is dependent on the particle size distribution of the soil. Cohesive soils have a significant proportion of fine-grained particles.

The fine-grained particles in a cohesive soil attract each other even in the absence of water. This is especially true when the finegrained particles include a significant amount of clay. Soils lacking a significant proportion of fine-grained particles will stick together

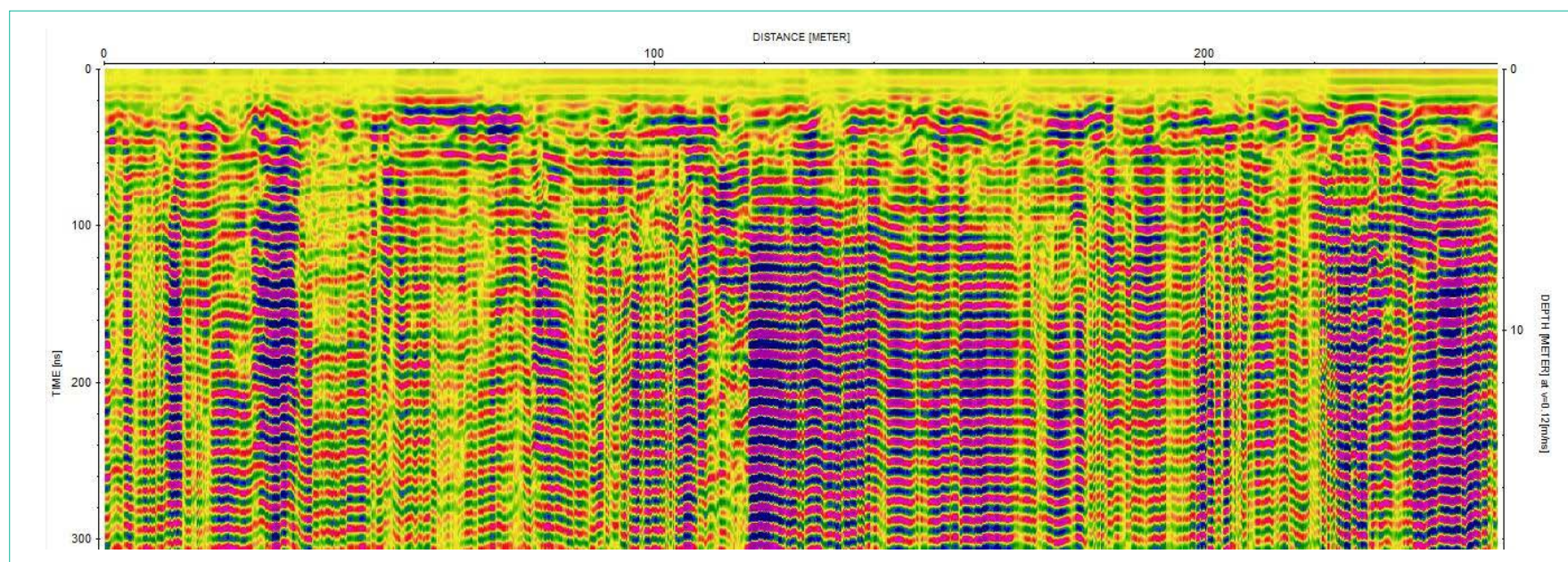

Figure 7: Line No. 1 made by using $100 \mathrm{MHz}$ antenna from East to West. 

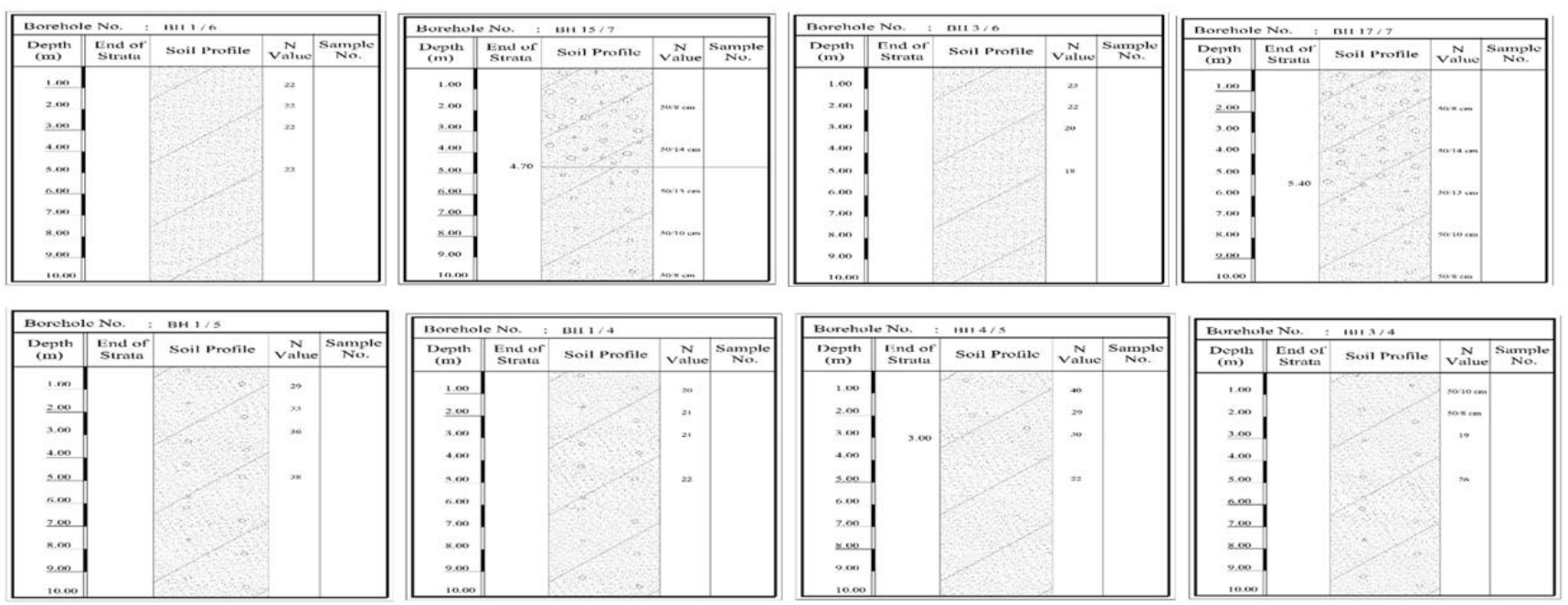

Figure 8: Shows a Geotechnical Section.

Table 2: Parameters Obtained from Grain Size Distribution Curve.

\begin{tabular}{|c|c|c|c|c|c|c|c|c|c|c|c|c|c|}
\hline \multirow{2}{*}{ Sample No. } & \multicolumn{8}{|c|}{ Sieve Size (mm) (Passing \%) } & \multirow{2}{*}{ D10 } & \multirow{2}{*}{ D30 } & \multirow{2}{*}{ D60 } & \multirow{2}{*}{ CU } & \multirow{2}{*}{ CG } \\
\hline & $>4$ & 4-2 & $2-1$ & $1-0.5$ & $0.5-0.25$ & $0.25-0.125$ & $0.125-0.06$ & $<0.06$ & & & & & \\
\hline $1 / 1(2 \mathrm{~m})$ & 100 & 76 & 52 & 38 & 24 & 19 & 15 & 11 & 0 & 0.59 & 2.7 & ----- & ----- \\
\hline $14 / 1(2 m)$ & 100 & 100 & 91 & 48 & 18 & 7 & 5 & 2 & 0.24 & 0.58 & 1.2 & 5 & 1.17 \\
\hline $30 / 1(2 \mathrm{~m})$ & 100 & 99 & 91 & 49 & 24 & 5 & 4 & 3 & 0.25 & 0.5 & 1.1 & 4.4 & 0.91 \\
\hline $33 / 1(2 m)$ & 100 & 100 & 93 & 48 & 22 & 8 & 3 & 2 & 0.22 & 0.53 & 1.1 & 5 & 1.16 \\
\hline $37 / 1(2 \mathrm{~m})$ & 100 & 100 & 89 & 59 & 29 & 5 & 4 & 3 & 0.23 & 0.42 & 0.85 & 3.7 & 0.9 \\
\hline $45 / 1(2 m)$ & 100 & 98 & 79 & 38 & 17 & 8 & 4 & 2 & 0.23 & 0.67 & 1.5 & 6.52 & 1.3 \\
\hline $9 / 2(8 m)$ & 100 & 82 & 79 & 70 & 29 & 9 & 6 & 4 & 0.2 & 0.42 & 0.72 & 3.6 & 1.23 \\
\hline $26 / 2(2 m)$ & 100 & 72 & 59 & 50 & 29 & 17 & 14 & 11 & 0 & 0.45 & 2.2 & ----- & ----- \\
\hline $33 / 2(3 m)$ & 100 & 65 & 51 & 49 & 31 & 21 & 18 & 16 & 0 & 0.4 & 3.6 & ----- & ----- \\
\hline $39 / 2(6 m)$ & 100 & 100 & 87 & 72 & 31 & 10 & 8 & 6 & 0.19 & 0.42 & 0.7 & 3.68 & 1.33 \\
\hline $45 / 2(2 m)$ & 100 & 63 & 49 & 39 & 24 & 19 & 14 & 11 & 0 & 0.57 & 4 & ------ & ----- \\
\hline $2 / 3(1 \mathrm{~m})$ & 100 & 71 & 43 & 36 & 29 & 16 & 14 & 11 & 0 & 0.45 & 3.4 & ----- & ----- \\
\hline 10/3 (1m) & 100 & 62 & 51 & 38 & 25 & 13 & 12 & 11 & 0 & 0.55 & 4 & ----- & ----- \\
\hline $18 / 3(2 \mathrm{~m})$ & 100 & 54 & 41 & 37 & 19 & 12 & 10 & 10 & 0 & 0.65 & 5.5 & ----- & ----- \\
\hline $26 / 3(2 m)$ & 100 & 63 & 44 & 31 & 29 & 13 & 12 & 11 & 0 & 0.6 & 4 & ----- & ----- \\
\hline $33 / 3(4 m)$ & 100 & 70 & 49 & 37 & 30 & 13 & 11 & 9 & 0.09 & 0.42 & 3.2 & 35.56 & 0.61 \\
\hline $45 / 3(3 m)$ & 100 & 85 & 68 & 40 & 29 & 12 & 11 & 9 & 0.09 & 0.45 & 1.7 & 18.89 & 1.32 \\
\hline $1 / 4(2 m)$ & 100 & 98 & 91 & 73 & 28 & 11 & 10 & 8 & 0.13 & 0.45 & 0.7 & 5.38 & 2.23 \\
\hline $3 / 4(3 m)$ & 100 & 81 & 73 & 41 & 32 & 12 & 10 & 9 & 0.1 & 0.4 & 1.5 & 15 & 1.07 \\
\hline $5 / 4(2 m)$ & 100 & 100 & 95 & 71 & 35 & 11 & 9 & 8 & 0.15 & 0.37 & 0.7 & 4.67 & 1.3 \\
\hline $11 / 4(4 m)$ & 100 & 100 & 96 & 83 & 34 & 11 & 10 & 9 & 0.1 & 0.38 & 0.6 & 6 & 2.41 \\
\hline $20 / 4(3 m)$ & 100 & 57 & 41 & 28 & 19 & 10 & 9 & 8 & 0.2 & 0.95 & 5.2 & 26 & 0.87 \\
\hline $1 / 5(2 \mathrm{~m})$ & 100 & 80 & 62 & 37 & 19 & 11 & 10 & 8 & 0.1 & 0.65 & 1.9 & 19 & 2.22 \\
\hline $4 / 5(5 \mathrm{~m})$ & 100 & 98 & 85 & 72 & 28 & 10 & 9 & 8 & 0.19 & 0.45 & 0.7 & 3.68 & 1.52 \\
\hline $6 / 5(3 m)$ & 100 & 82 & 68 & 41 & 22 & 13 & 12 & 11 & 0 & 0.57 & 1.6 & ----- & ----- \\
\hline
\end{tabular}




\begin{tabular}{|c|c|c|c|c|c|c|c|c|c|c|c|c|c|}
\hline $1 / 6(2 \mathrm{~m})$ & 100 & 100 & 98 & 83 & 34 & 10 & 8 & 7 & 0.19 & 0.39 & 0.62 & 3.26 & 1.29 \\
\hline $3 / 6(5 m)$ & 100 & 98 & 84 & 72 & 28 & 10 & 9 & 8 & 0.19 & 0.45 & 0.7 & 3.68 & 1.52 \\
\hline $5 / 6(2 m)$ & 100 & 100 & 96 & 81 & 32 & 8 & 8 & 7 & 0.2 & 0.4 & 0.63 & 3.15 & 1.27 \\
\hline $6 / 6(3 m)$ & 100 & 81 & 67 & 41 & 22 & 11 & 10 & 10 & 0 & 0.59 & 1.7 & ------ & ------ \\
\hline $8 / 6(2 m)$ & 100 & 91 & 61 & 38 & 22 & 10 & 9 & 8 & 0.19 & 0.6 & 1.9 & 10 & 1 \\
\hline $10 / 6(6 \mathrm{~m})$ & 100 & 87 & 71 & 31 & 20 & 9 & 7 & 7 & 0.2 & 0.8 & 1.7 & 8.5 & 1.88 \\
\hline $1 / 7(3 \mathrm{~m})$ & 100 & 79 & 35 & 19 & 10 & 7 & 6 & 5 & 0.43 & 1.6 & 3.3 & 7.67 & 1.8 \\
\hline $8 / 7(2 \mathrm{~m})$ & 100 & 72 & 30 & 17 & 10 & 9 & 7 & 6 & 0.43 & 2 & 3.8 & 8.84 & 2.45 \\
\hline $15 / 7(2 m)$ & 100 & 58 & 50 & 39 & 29 & 21 & 17 & 15 & 0 & 0.45 & 5 & ------ & ----- \\
\hline $17 / 7(1 \mathrm{~m})$ & 100 & 74 & 61 & 48 & 37 & 23 & 20 & 17 & 0 & 0.29 & 1.9 & ------ & ------ \\
\hline $29 / 7(7 \mathrm{~m})$ & 100 & 70 & 41 & 22 & 10 & 9 & 8 & 8 & 0.43 & 1.3 & 3.5 & 8.14 & 1.12 \\
\hline $38 / 7$ (2m) & 100 & 60 & 41 & 36 & 28 & 17 & 13 & 11 & 0 & 0.5 & 4.8 & ------ & ----- \\
\hline
\end{tabular}

when wet, but they disaggregate into individual grains or pieces after drying.

These soils are cohesionless or non-cohesive. The importance of soil to the work of engineering geologists stems from its role in construction.

Firstly, the soil is one of the most common building materials. It is present, usually in abundant quantities, almost anywhere something is to be built.

Secondly, structures are commonly founded on the soil. This influences the design of a structure It may require that a building have a particular type of foundation such as a spread footing. The soil may indicate the need for a structural design more tolerant of deformation.

Thirdly, it is important to know whether the soil on natural slopes adjacent to construction will remain in place.

The soils at west Kom Umbo are classified into graded sand and gravel some silt, compacted sand some silt, and gravel.

In the present work, the laboratory tests on graded sand, gravel, and silt are sieves analysis of the classification of soil.

\section{Sieves analysis}

The sieves are normally designed to some standard e.g. British standard B.S. 1377 and (1967).

The weight of the sample retained on any sieve is measured and expressed as a percentage of the whole sample passing that sieve. the shape of the particle size distribution curves can be expressed approximately by a uniformity coefficient, defined as the ratio D60/ $\mathrm{D} 10$, where D60 and D10 are the particle sizes corresponding to the cumulative percentages 60 and 10 respectively. The results of this test are as follows.

This type of soils has good load-bearing capacities and good drainage qualities, and their strength and volume change characteristics are not significantly affected by a change in moisture conditions.

Uniformity Coefficient: The one result of the classification of sand is the particle size distribution curve, which gives an idea about the type and gradation of the soil. The soil sample may be either well graded or poorly graded. The well-graded soil contains particles of all sizes well represented, while poorly graded soil has a deficiency of certain particles. By studying the particle size distribution, we obtain uniformity coefficient, which is known as the measure of the particle size range and effective diameter as follows:

- Uniformity coefficient $\mathrm{Cu}$ (a measure of the particle size range).

$\mathrm{Cu}$ is also called Hazen Coefficient $\rightarrow \mathrm{Cu}=\mathrm{D} 60 / \mathrm{D} 10$

- Coefficient of gradation or Coefficient of curvature Cg.

$\mathrm{Cg}=(\mathrm{D} 30) 2 / \mathrm{D} 60 \times \mathrm{D} 10$

Where:

D60\% is the particle size diameter at which $60 \%$ of the soil is finer.

$\mathrm{D} 10 \%$ is the particle size diameter at which $10 \%$ of the soil is finer.

The diameter D10\% is known as the effective diameter and is used in estimating some of the mechanical properties of soil. The value of $\mathrm{U}$ of unity usually means that the soil in which the grains are partially all of the same sizes where the minimum possible value of $U$ is unity and the large coefficient corresponds to a graded soil from finer to coarser.

\section{$\mathrm{Cu}<5$ : Very Uniform.}

$\mathrm{Cu}=5$ : Medium Uniform.

$\mathrm{Cu}>5$ : Non-Uniform.

While: Cg (from 1 to 3): Well graded.

The results of these tests discussed in (Table 2). This type of soils have good load-bearing capacities and good drainage qualities, and their strength and volume change characteristics are not significantly affected by a change in moisture conditions.

The results of the uniformity coefficient $(\mathrm{Cu})$ ranging between 3.15 (Very uniform) to 35.56 (Non-uniform). The results of the coefficient of gradation range between 0.61 (poorly graded) to 2.41 (Well graded).

We could not obtain the values of D60, D30 and D10 from the 


\begin{tabular}{|c|c|c|c|c|c|c|c|}
\hline \multirow{2}{*}{ COBBLES } & \multirow{2}{*}{ GRAVEL } & \multicolumn{2}{|c|}{ SAND } & \multicolumn{3}{|c|}{ SILT } & \multirow{2}{*}{ CLAY } \\
\hline & & Coarse to Medium & Fine & Coarse & Medium & Fine & \\
\hline
\end{tabular}

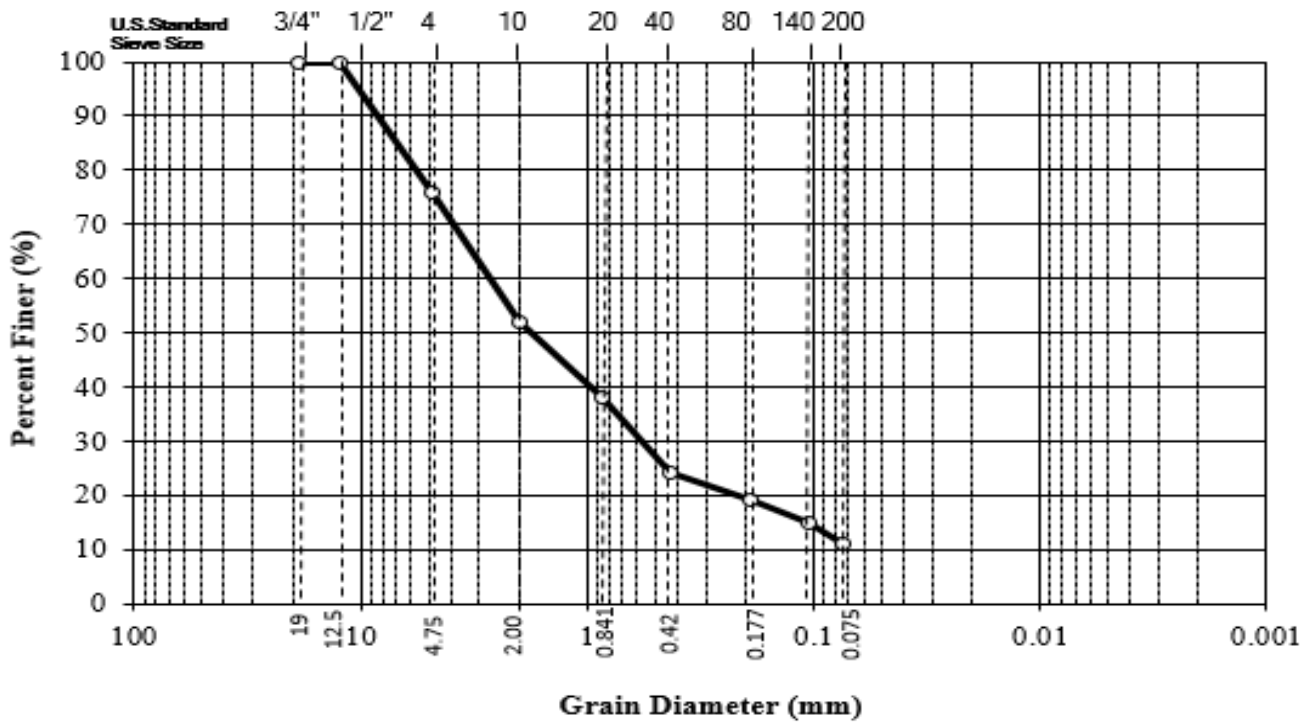

Figure 9: Grain Size Distribution Curve.

GSD curve to calculate the values of $\mathrm{Cu}$ and $\mathrm{Cg}$ for some of the samples, as they are fine-grained soils with particle sizes less than the smallest sieve size used in Sieve Analysis Test (Figure 9).

\section{Conclusion}

The present works have been carried out to study the geophysical and engineering properties of the bed to evaluate the soil foundations in the area of West Kom Umbo.

According to the quantitative interpretation of the geoelectric sounding curves, the number of observed layers is two. The first layer consists of gravel sand, which has a resistivity range from 4189 to 38033 , and the second layer is sand, which has a resistivity value ranging from 1224 to $9682 \Omega . \mathrm{m}$. Also, the thicknesses of these layers vary from a sounding station to the other.

According to the Ground Penetrating Radar GPR data displaying $2 \mathrm{D}$ profiles that contain the expected anomalies. Because the study area is saturated with silty sand and gravel, part of radar waves is attenuated and the reflections from the subsurface materials are weak. Results with the $100 \mathrm{MHz}$ antennae are the resistive sand, gravel is a very good GPR target, and horizontal layering and stratification are evident throughout the deposit. The study also proved that there are no voids or cracks under the surface and that the soil is homogeneous.

According to the engineering studies on samples collected from different sites in the study area reveal that, the results of uniformity coefficient $(\mathrm{Cu})$ ranging between 3.15 (Very uniform) to 35.56 (Nonuniform). The results of the coefficient of gradation range between 0.61 (poorly graded) to 2.41 (Well graded).

From the integration of geophysical and geotechnical studies, it becomes clear that there are two subsurface layers that were not affected by any structure. Also, this research can conclude that there is a direct relationship between the size of the soil grains, the electrical resistivity and the extent of the homogeneity of the soil, as the greater the size of the soil grains, the greater the electrical resistivity and the less uniformity between the grains.

\section{References}

1. Koch M, Gaber A, Mohamed HG, El-Sayed Z, Sayed MA, Mostafa A. Multisensor characterization of subsurface structures in a Desert Plain Area in Egypt with implications for groundwater exploration. (in proceeding of SPIE, Germany,V.8887 888712-2). 2013.

2. Said R. The geology of Egypt, El-Sevier publishing company Amsterdam, New York. 1962: 377

3. Zaghloul EA. Geology of Abu Minqar-Farafra-Ain Dalla stretch, Western Desert, Egypt. Ph. Theses. Cairo Univ. 1983: 228.

4. Hewaidy AA, Soliman SI. Stratigraphy and paleocology of Gebel El-Borga, Southwest Kom Ombo, Nile Valley, Egypt. Egyptian Journal of Geology. 1993; 37: 299-321.

5. Egypte. Geological Survey \& Issawi B. The Phanerozoic geology of Egypt: a geodynamic approach. Ministry of Petroleum. The Egyptian Mineral Resourse Authority. 2009.;

6. EGSMA, NARSS, UNDP \& UNESCO. "Geologicalmap of Aswan, Quadrangle, Egypt”. Sheet NG-36 B with scale 1:250 000. 2005.

7. Abd El-Razik T \& Razavaliaev A. On the tectonic origin of the Nile Valley between Idfu and Qena. Egypt Journal of Geology. 1972; 16: 235-245.

8. Youssef Ml. Structural pattern of Egypt and its interpretation. Am. Assoc. Petrol. Geol. Bull. 1968; 52: 601-614.

9. Gaber A, Koch M, El-Baz F. Textural and compositional characterization of Wadi Feiran Deposits, Sinai Peninsula, Egypt, using Radarsat-1, PALSAR, SRTM and ETM+ data. Journal of Remote Sensing. 2010; 2: 52-75.

10. Sandmeier KJ. Program for processing and interpretation of Reflection and Transmission data, Karlsruhe, Germany. 2001. 
11. Cassidy NJ. Ground penetrating radar data processing, modelling and analysis. In Ground penetrating radar: theory and applications. Jol HM (ed). Elsevier: Amsterdam. 2009; 141-176.

12. ASTM: Annual book of ASTM standard. Standard test methods for laboratory determination of swelling pressure of soil, D2435, Vol. 0408, Feladelifia. 1996.

13. Kurniawan ALVA. Basic principles in using IPI2 Win Software. 2009. 